\title{
Synthesis, Characterization and Catalytic Performance of a Novel Picolinic Acid-12-Molybdophosphoric Acid Hybrid Catalyst
}

\author{
Lijun Liu, Honghong Wang, Shuwen Gong, *Jing Lu* and Qian Zhang \\ Institute of Organic Functional Molecules and Materials, School of Chemistry and Chemical \\ Engineering, Liaocheng University, 252000 Liaocheng, China
}

\begin{abstract}
A novel 12-molybdophosphoric acid (HPM)-based complex $\left(\mathrm{H}_{2} \mathrm{PI}\right)_{2}\left(\mathrm{H}_{3} \mathrm{O}\right)\left[\mathrm{PMo}_{12} \mathrm{O}_{40}\right]$ $\left[\mathrm{Mo}_{2} \mathrm{O}_{5}\left(\mathrm{H}_{2} \mathrm{O}\right)_{2}(\mathrm{PI})_{2}\right] \cdot 11 \mathrm{H}_{2} \mathrm{O}(\mathrm{PI}-\mathrm{HPM})$ was prepared by modification with picolinic acid (HPI) and characterized by the methods of Fourier transform infrared (FTIR) spectroscopy, thermogravimetry (TG), X-ray powder and single crystal diffraction. The complex retained the classical Keggin structure of bulk HPM, there were some strong hydrogen bonds existing between the $\left[\mathrm{PMo}_{12} \mathrm{O}_{40}\right]^{3-}$ polyanion, the $\left[\mathrm{Mo}_{2} \mathrm{O}_{5}\left(\mathrm{H}_{2} \mathrm{O}\right)_{2}(\mathrm{PI})_{2}\right]$ coordination moiety, the protonated HPI and the lattice water molecules. Then PI-HPM was employed as heterogeneous catalyst for esterification reaction to evaluate its acid-catalytic activity. The complex exhibited high activity and good durability in reaction mixtures, indicating that it was a promising heterogeneous acid catalyst for esterification that including the conversion of oleic acid to oleates.
\end{abstract}

Keywords: heteropoly acid, picolinic acid, heterogeneous catalysis, acid catalyst, esterification

\section{Introduction}

Acid catalyzed reaction is one of the most important reactions, including esterification, acetalization, etherification, nitration reaction and so on. ${ }^{1-5}$ Conventional acid catalysts that are widely used in industries are mineral acids, such as $\mathrm{H}_{2} \mathrm{SO}_{4}, \mathrm{H}_{3} \mathrm{PO}_{4}, \mathrm{HCl}, \mathrm{CF}_{3} \mathrm{COOH}$ and $\mathrm{ClSO}_{2} \mathrm{OH}^{6,7}$ These liquid acids have excellent catalytic activities, but they suffer from several drawbacks, such as the corrosiveness, the existence of side reactions and difficulty of separation from the reaction mixtures. ${ }^{7,8}$ Due to stringent and growing environmental regulations, the chemical industry needs the development of environmentfriendly synthetic methodologies. Heterogeneous acids, which have low corrosion, reusability and high acidity, are considered to be the suitable substitutes for liquid acids. ${ }^{9,10}$ Taking esterification reaction as an example, some heterogeneous acids have gained attention, which included ion exchange resins, zeolites, sulfated oxides, biomass carbon-based solid acid and heteropoly acids (HPAs). ${ }^{6,11-17}$

HPAs are typical strong Brønsted acids with low volatility, low corrosiveness and flexibility. ${ }^{11,17}$ However, as a heterogeneous catalyst, the disadvantages of HPAs lie in their low surface area (1-10 $\left.\mathrm{m}^{2} \mathrm{~g}^{-1}\right)$ and solubility in

*e-mail: gshw76@163.com; lujinglcu@163.com polar solvents. ${ }^{17,18}$ Therefore, supported HPAs and salts of HPAs are developed to overcome the abovementioned problems. ${ }^{2-4,17-20}$ Although these technologies can obviously improve the separation problem of HPAs from reaction system, the acid strength of supported HPAs and salts of HPAs was commonly lower than that of bulk HPAs. ${ }^{21}$ The supported HPAs materials also suffered from the leaching of HPAs active species in polar reaction media. Therefore, it is still desirable to design new HPAs catalysts suitable for application in polar reaction mixtures.

In previous works, it was reported that there is strong electronic interaction between the metal oxygen cluster and the organic segment for organic compound modified hybrid HPAs catalysts. ${ }^{22-24}$ So we considered modifying HPAs by heterocyclic aromatic compounds containing carboxylic acid group. ${ }^{25}$ The initial idea was to combine the HPAs with aromatic compound basis on the existing electronic interaction, which was different from supporting and salification. The combination would decrease the solubility and improve the durability of HPAs in polar mixtures. At the same time, the carboxylic acid group may be favorable to improve the acidity of the complex. In this paper, a novel picolinic acid (HPI)-12-molybdophosphoric acid (HPM) hybrid complex was prepared and characterized. The prepared complex was applied in esterification as heterogeneous catalyst to evaluate acid-catalytic activity. More interestingly, the single crystal of the modified 
complex was obtained, which helped to reveal the combination between HPM and HPI.

\section{Experimental}

\section{Synthesis of catalysts}

All solvents and reagents were purchased commercially and used as received without any further purification. The aqueous solution of HPI and HPM were prepared; $0.002 \mathrm{~mol}(0.246 \mathrm{~g}) \mathrm{HPI}$ (Aladdin Industrial Corporation) were dissolved in $5 \mathrm{~mL}$ distilled water, and $0.001 \mathrm{~mol}$ (1.825 g) HPM (Sinopharm Chemical Reagent Co., Ltd.) were dissolved in $10 \mathrm{~mL}$ distilled water. Then the solution of HPI was slowly dropped to the solution of HPM under vigorous stirring at room temperature. After stirring for $2 \mathrm{~h}$, the resulting green precipitate was filtered. The prepared sample was dried at $110^{\circ} \mathrm{C}$ and collected as investigated catalyst that was referred to as picolinate (PI)-HPM.

When the green precipitate was filtered, the filtrate was placed carefully and allowed to diffuse. After two weeks, the green single crystal of PI-HPM was obtained.

\section{Characterization}

X-Ray powder diffraction (XRD) analysis was carried out using a XD-3 diffractometer (Beijing Purkinje General Instrument Co. Ltd.) with $\mathrm{Cu} \mathrm{K}_{\alpha}(1.542 \AA)$ radiation.

$\mathrm{X}$-Ray single crystal diffraction data was collected on a Bruker SMART 1000 CCD diffractometer, equipped with graphite-monochromated $\mathrm{Mo} \mathrm{K}_{\alpha}$ radiation with a radiation wavelength of $0.71073 \AA$ by using the $\omega$-scan technique. The structure was solved by direct method and refined by full-matrix squares on $\mathrm{F}^{2}$ using SHELXTL program. All non-hydrogen atoms were refined anisotropically. Positions of the hydrogen atoms were geometry placed and refined isotropically as a riding mode. The crystal data of the complex was deposited in the Cambridge Crystallographic Data Centre with the CCDC number 1412295. The refinement crystal data and the selected bond parameters are listed in Tables S1 and S2 (Supplementary Information).

Fourier transform infrared (FTIR) spectra were recorded on a Thermo Nicolet 6700 FTIR spectrometer in $\mathrm{KBr}$ matrix in the range of $400-2000 \mathrm{~cm}^{-1}$.

Thermal analysis was carried out using a PYRTSI thermal analyzer. The samples with mass of about $10 \mathrm{mg}$ were placed in alumina crucible. The measurements were performed with a heating rate of $10{ }^{\circ} \mathrm{C} \mathrm{min}-1$ in dynamic nitrogen atmosphere with the flow rate of $50 \mathrm{~mL} \mathrm{~min}^{-1}$.

Elemental analysis $(\mathrm{C}, \mathrm{H}$ and $\mathrm{N}$ ) was performed on a PerkinElmer 2400 elemental analyzer, whereas the metal content was determined by inductively coupled plasma (ICP) analysis on a PerkinElmer Optima 2000DV ICP spectrometer. Anal. calcd. for single crystal $\left(\mathrm{C}_{24} \mathrm{H}_{49} \mathrm{Mo}_{14} \mathrm{~N}_{4} \mathrm{O}_{67} \mathrm{P}, 2839.80\right): \mathrm{C}, 10.14 ; \mathrm{H}, 1.73 ; \mathrm{N}, 1.97$; Mo, 47.33; P, 1.09; elemental analysis for PI-HPM powder: C, 9.97; H, 1.76; N, 2.01; Mo, 46.85; P, 1.04 .

For HPM and PI-HPM, the capacity of acid sites was determined by acid-base titration. An amount of ca. $0.05 \mathrm{~g}$ of each sample was suspended in $15 \mathrm{~mL}$ distilled water for $2 \mathrm{~h}$ at room temperature. Then the sample was titrated with $0.1 \mathrm{~mol} \mathrm{~L}^{-1} \mathrm{NaOH}$. The acidity was determined by the following equation:

Acidity $=\frac{\mathrm{C}_{\mathrm{NaOH}} \mathrm{V}_{\mathrm{NaOH}}}{\mathrm{m}_{\mathrm{HPM} \text { or PI-HPM }}}$

where $\mathrm{C}_{\mathrm{NaOH}}$ and $\mathrm{V}_{\mathrm{NaOH}}$ are the concentration and volume of $\mathrm{NaOH}$, respectively, and $\mathrm{m}_{\mathrm{HPM} \text { or PI-HPM }}$ is the mass of the acid.

\section{Catalytic tests}

Esterification reactions of carboxylic acids besides oleic acid with alcohols were carried out in a $100 \mathrm{~mL}$ round-bottomed flask equipped with a reflux condenser at atmospheric pressure. In a typical run, $0.1 \mathrm{~mol}(6.0 \mathrm{~g})$ acetic acid, $0.3 \mathrm{~mol}(13.8 \mathrm{~g})$ ethanol and $0.1 \mathrm{~g}$ catalyst were added into the round bottom flask. After stirring for a certain reaction time at the reflux temperature, the catalyst was filtered and the product was determined using a gas chromatograph with flame ionization detector (FID).

Esterification reactions of oleic acid with alcohols were carried out in a $50 \mathrm{~mL}$ gas-tight batch reactor with a magnetic stirrer, and an oil bath was used to maintain the reaction temperature. In a typical run, 0.07 g PI-HPM ( 5 wt.\% (0.5 mol\%) of oleic acid) were added to the mixture of oleic acid $(5 \mathrm{mmol}, 1.41 \mathrm{~g})$ with methanol ( $50 \mathrm{mmol}, 1.6 \mathrm{~g})$, after stirring for $6 \mathrm{~h}$ at desired temperature $\left(40,60,80\right.$ or $\left.100{ }^{\circ} \mathrm{C}\right)$. The products were identified by comparison with the authentic samples and finally by gas chromatography-mass spectrometry (GC-MS). The conversion of oleic acid was determined using an Agilent 6890 gas chromatograph equipped with a HP-5MS capillary column and FID detector; methyl caprylate was selected as internal standard.

Stability test of the PI-HPM was carried out by running four consecutive experiments under the same reaction conditions (mole ratio of methanol to oleic acid: 10:1, reaction temperature: $80{ }^{\circ} \mathrm{C}$, catalyst amount: $10 \mathrm{wt} . \%$ of the weight of oleic acid and reaction time: $6 \mathrm{~h}$ ). Between the catalytic experiments, the catalyst was separated from the reaction mixture by filtration, washed with methanol and dried at $110^{\circ} \mathrm{C}$. 


\section{Results and Discussion}

Catalyst characterization

Single crystal X-ray diffraction revealed that the PI-HPM crystallizes in triclinic crystal system, P-1 space group. In PI-HPM, there exists one classical Keggin-type $\left[\mathrm{PMo}_{12} \mathrm{O}_{40}\right]$ metal oxygen cluster, one $\left[\mathrm{Mo}_{2} \mathrm{O}_{5}\left(\mathrm{H}_{2} \mathrm{O}\right)_{2}(\mathrm{PI})_{2}\right]$ coordination moiety, two protonated isolated HPI and twelve lattice water molecules, where one additional proton had to reside (Figure 1). The $\left[\mathrm{PMo}_{12} \mathrm{O}_{40}\right]$ polyanion shows a classical Keggin-type structure. It was formed by a central $\mathrm{PO}_{4}$ tetrahedron surrounded by four $\mathrm{Mo}_{3} \mathrm{O}_{13}$ groups, in which three $\mathrm{MoO}_{6}$ octahedra shared edges. One $\mathrm{PO}_{4}$ tetrahedron and twelve $\mathrm{MoO}_{6}$ octahedra from four $\mathrm{Mo}_{3} \mathrm{O}_{13}$ groups shared corners and made up the Keggin-type $\left[\mathrm{PMo}_{12} \mathrm{O}_{40}\right]$ cluster. For the $\left[\mathrm{Mo}_{2} \mathrm{O}_{5}\left(\mathrm{H}_{2} \mathrm{O}\right)_{2}(\mathrm{PI})_{2}\right]$ coordination moiety, each molybdenum cation was coordinated by two terminal oxygen atoms, one oxygen atom from one water molecule, one bridging oxygen atom, and finally chelated by one PI anion through its nitrogen and carboxylate oxygen atoms. These two molybdenum centers were linked to each other by the bridging oxygen atom to form a dinuclear coordination moiety. As shown in Figure 2, there are some strong hydrogen bonds existing between the $\left[\mathrm{PMo}_{12} \mathrm{O}_{40}\right]^{3-}$ polyanion, the $\left[\mathrm{Mo}_{2} \mathrm{O}_{5}\left(\mathrm{H}_{2} \mathrm{O}\right)_{2}(\mathrm{PI})_{2}\right]$ coordination moiety, the protonated HPI and the lattice water molecules, and the parameters of the hydrogen bonds are listed in Table 1.

The bond-valence calculations revealed that all Mo are in their +6 oxidation states, $\mathrm{P}$ is +5 and each of the oxygen atoms on the $\left[\mathrm{PMo}_{12} \mathrm{O}_{40}\right]$ cluster are -2 . Therefore, the total charge of this cluster is -3 . For the $\left[\mathrm{Mo}_{2} \mathrm{O}_{5}\left(\mathrm{H}_{2} \mathrm{O}\right)_{2}(\mathrm{PI})_{2}\right]$ unit, the overall charge is 0 . The free picolinic acid groups were each protonated, each yielding $\left(\mathrm{H}_{2} \mathrm{PI}\right)^{+}$. The additional charge $\left(1 \mathrm{H}^{+}\right)$should be residing on one of the non-coordinated 12 lattice water molecules. The molecular formula is therefore $\left(\mathrm{H}_{2} \mathrm{PI}\right)_{2}\left(\mathrm{H}_{3} \mathrm{O}\right)\left[\mathrm{PMo}_{12} \mathrm{O}_{40}\right]$ $\left[\mathrm{Mo}_{2} \mathrm{O}_{5}\left(\mathrm{H}_{2} \mathrm{O}\right)_{2}(\mathrm{PI})_{2}\right] \cdot 11 \mathrm{H}_{2} \mathrm{O}$.

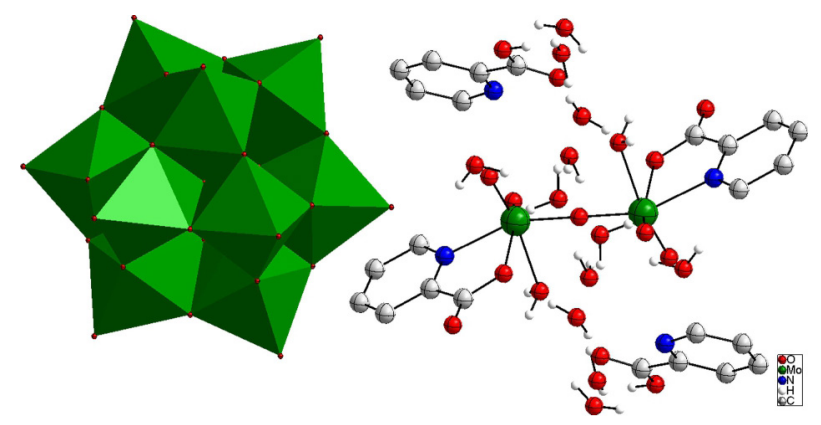

Figure 1. The crystallographic unique unit of PI-HPM.

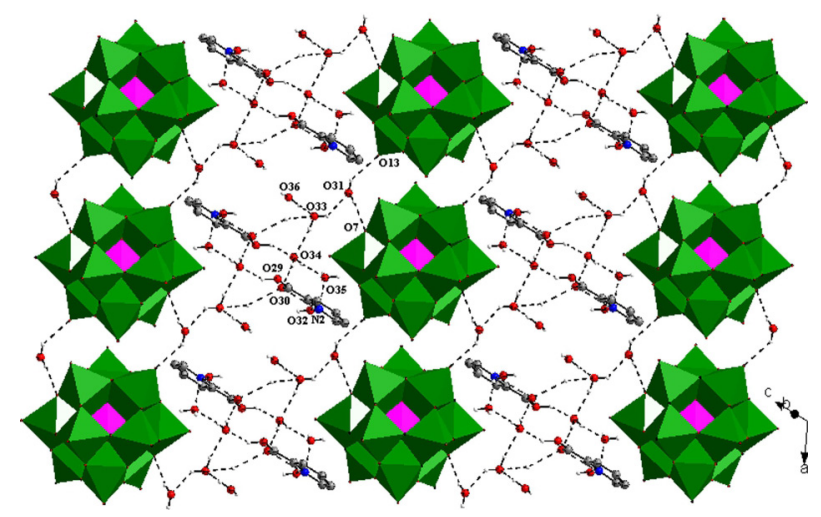

Figure 2. The complicated hydrogen bonds in the PI-HPM complex.

The XRD pattern of PI-HPM is presented in Figure 3. For comparison, the XRD patterns of raw HPM and HPI are also displayed. Pure HPM shows the characteristic pattern in the Keggin polyanion that matched with literature very well. ${ }^{18,26}$ The diffraction peaks of PI-HPM were observed mainly in the four ranges of $2 \theta=6-10,16-20,25-30$ and $33-35^{\circ}$, so it can be deduced that PI-HPM still maintained the Keggin structure of raw HPM. ${ }^{27}$ But PI-HPM exhibited very different diffraction peaks from that of raw HPM and no diffraction peaks of HPI were detected, suggesting that PI-HPM was a new crystal phase but not the simple mixture of HPM and HPI. This conclusion agreed well with the result of single crystal diffraction study.

The single crystal particles that were obtained through solvent evaporation were collected and analyzed by XRD;

Table 1. Hydrogen bond parameters in the PI-HPM

\begin{tabular}{|c|c|c|c|c|c|c|c|}
\hline $\mathrm{D}-\mathrm{H} \cdots \mathrm{A}$ & $\mathrm{d}_{(\mathrm{H} . \mathrm{A})} / \AA$ & $\angle \mathrm{DHA} /$ degree & $\mathrm{d}_{(\mathrm{D} . \mathrm{A})} / \AA$ & D-H $\cdots A$ & $\mathrm{~d}_{(\mathrm{H.. \textrm {A } )}} / \AA$ & $\angle \mathrm{DHA} /$ degree & $\mathrm{d}_{(\mathrm{D} . \mathrm{A})} / \AA$ \\
\hline $\mathrm{N} 2-\mathrm{H} \cdots \mathrm{O} 30$ & 1.922 & 161.12 & 2.75 & $\mathrm{O} 27-\mathrm{H} \cdots \mathrm{O} 32$ & 2.411 & 152.53 & 3.19 \\
\hline $\mathrm{O} 29-\mathrm{H} \cdots \mathrm{O} 34$ & 1.702 & 158.55 & 2.483 & $\mathrm{O} 30-\mathrm{H} \cdots \mathrm{O} 35$ & 1.889 & 139.25 & 2.593 \\
\hline $\mathrm{O} 30-\mathrm{H} \cdots \mathrm{O} 22$ & 2.077 & 167.16 & 2.912 & $\mathrm{O} 31-\mathrm{H} \cdots \mathrm{O} 6$ & 2.316 & 143.47 & 3.041 \\
\hline O31-H $\cdots \mathrm{O} 19$ & 2.338 & 169.91 & 3.179 & $\mathrm{O} 34-\mathrm{H} \cdots \mathrm{O} 35$ & 1.866 & 159.29 & 2.678 \\
\hline $\mathrm{O} 33-\mathrm{H} \cdots \mathrm{O} 31$ & 2.091 & 122.46 & 2.646 & $\mathrm{O} 34-\mathrm{H} \cdots \mathrm{O} 33$ & 2.059 & 166.4 & 2.892 \\
\hline $\mathrm{O} 35-\mathrm{H} \cdots \mathrm{O} 23$ & 2.164 & 161.47 & 2.982 & $\mathrm{O} 35-\mathrm{H} \cdots \mathrm{O} 7$ & 2.604 & 144.43 & 3.333 \\
\hline O36-H.. O9 & 2.191 & 147.9 & 2.946 & $\mathrm{O} 36-\mathrm{H} \cdots \mathrm{O} 33$ & 1.954 & 146.67 & 2.704 \\
\hline
\end{tabular}




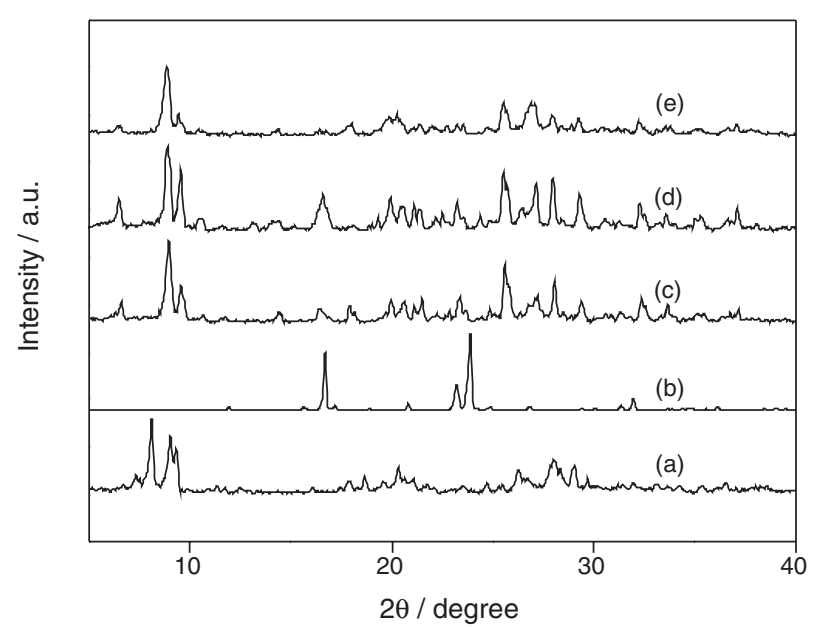

Figure 3. XRD patterns of (a) HPM; (b) HPI; (c) PI-HPM precipitate; (d) PI-HPM crystal and (e) PI-HPM after fourth use.

the pattern is also shown in Figure 3. It can be seen that the crystals show similar pattern to that of the PI-HPM precipitate, which indicated that these crystals have same structure as PI-HPM precipitate.

The FTIR spectra of HPM, HPI and PI-HPM are illustrated in Figure 4. The four bands for bulk HPM at 1062, 960, 868 and $783 \mathrm{~cm}^{-1}$ are due to the stretching mode of $\mathrm{P}-\mathrm{O}$ in central tetrahedral, $\mathrm{Mo}=\mathrm{O}_{\text {terminal }}$, $\mathrm{Mo}-\mathrm{O}-\mathrm{Mo}_{\text {(corner-sharing) }}$ and $\mathrm{Mo}-\mathrm{O}-\mathrm{Mo}_{\text {(edge-sharing) }}$ in its Keggin structure, respectively. ${ }^{23,26,28}$ There are four bands (1062, 961,872 and $797 \mathrm{~cm}^{-1}$ ) within the range of $700-1100 \mathrm{~cm}^{-1}$ in the spectra of PI-HPM that were similar with HPM, which revealed that the Keggin structure of the HPM was well maintained after modification with HPI. The characteristic bands of HPI located at 1655, 1354, 1298 and $765 \mathrm{~cm}^{-1}$ were also observed for PI-HPM, verifying the presence of HPI in the complex, which was consistent with the result of single crystal X-ray diffraction. And the pattern of PI-HPM showed clear evidence for the presence of the

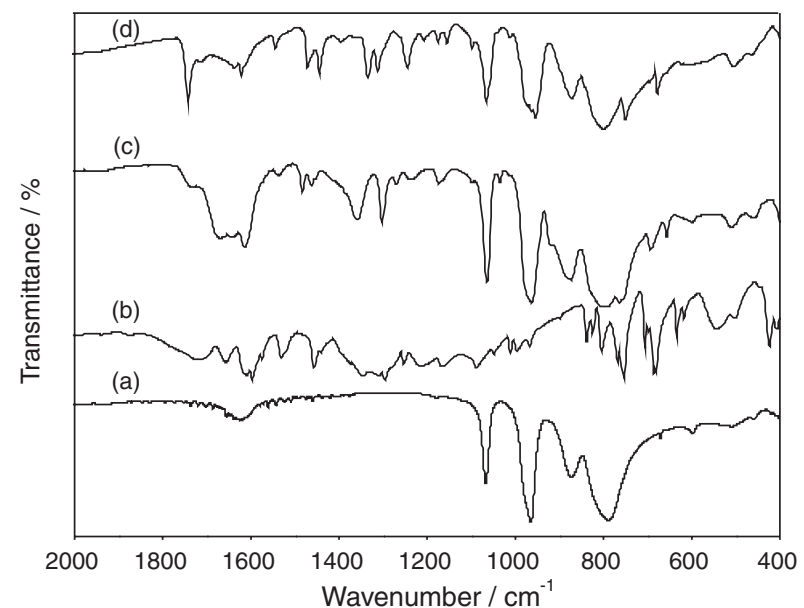

Figure 4. FTIR spectra of (a) HPM; (b) HPI; (c) PI-HPM and (d) PI-HPM after fourth use. pyridinium ion band at $1536 \mathrm{~cm}^{-1}$, which was absent in the IR spectrum of HPM. ${ }^{23,29}$

Thermal analyses were carried out on bulk HPM, HPI and PI-HPM to determine the thermal stability and the results are reported in Figure 5. The thermogravimetry (TG) of HPM showed a weight loss of about $8.6 \%$ up to a temperature of $130{ }^{\circ} \mathrm{C}$, indicating the loss of free and physical adsorbed water. ${ }^{21}$ The gradual weight loss of about $2.4 \%$ up to $716^{\circ} \mathrm{C}$ corresponded to the mass loss due to the reaction between acidic protons and structural oxygen from HPM, releasing water, followed by sharp decomposition to $\mathrm{MoO}_{3}$ and $\mathrm{PO}_{\mathrm{x}}$ species. ${ }^{30,31}$ PI-HPM exhibited similar weight loss at about 130 and $720^{\circ} \mathrm{C}$ like raw HPM, which also can be attributed to the loss of free and adsorbed water (the calculated amount is $7.6 \%$ ) and decomposition of raw HPM, respectively. In contrast with HPM and HPI, the quick weight loss of HPI at about $160{ }^{\circ} \mathrm{C}$ did not occur in the TG profile of PI-HPM, but a new weight loss around $310^{\circ} \mathrm{C}$ appeared and the percentage of weight loss was about $17.1 \%$ (from $91.7 \%$ at $310{ }^{\circ} \mathrm{C}$ to $74.6 \%$ at $550{ }^{\circ} \mathrm{C}$ ), which was close to the theoretical value content of HPI in the PI-HPM (the calculated amount is $17.3 \%$ ). Therefore, it can be considered that the PI-HPM was thermally stable in temperatures less than $310^{\circ} \mathrm{C}$. PI-HPM decomposed in the temperature range of $310-550^{\circ} \mathrm{C}$, indicating that PI-HPM was less thermally stable than pure HPM.

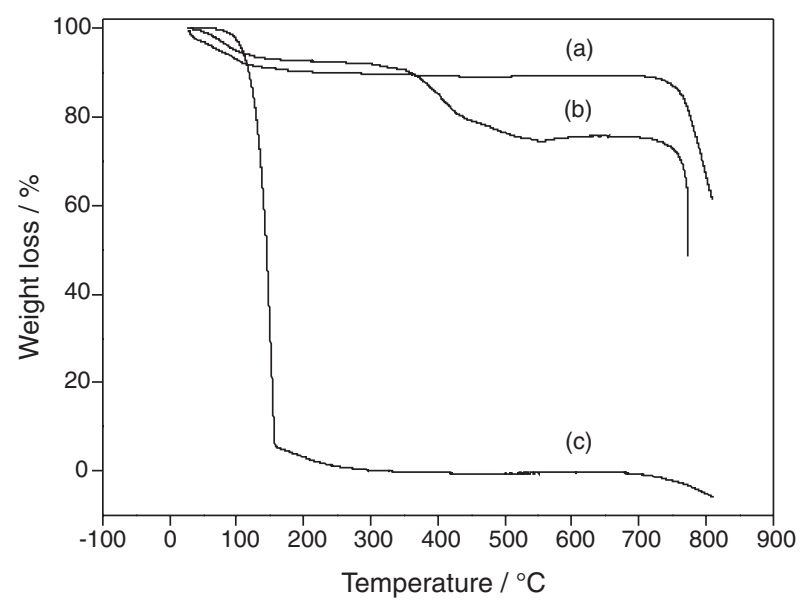

Figure 5. TG curves of (a) HPM; (b) PI-HPM and (c) HPI.

\section{Catalytic activity}

As acid catalyst, PI-HPM was applied to esterification reaction to evaluate its catalytic activity and these results are listed in Table 2. Acetic acid, $n$-propionic acid and $n$-hexanoic acid were subjected to esterification reaction with methanol, ethanol, $n$-propanol and $n$-butanol. It was found that PI-HPM exhibited excellent catalytic activity in these reactions and high conversions of carboxylic acids 
Table 2. Esterification reactions of carboxylic acids with alcohols over PI-HPM catalyst

\begin{tabular}{lcccc}
\hline entry & Catalyst & Acid (A) & Alcohol (B) & Conversion /\% \\
\hline 1 & PI-HPM & acetic acid & methanol & $100^{\mathrm{a}}$ \\
2 & PI-HPM & acetic acid & ethanol & 96.3 \\
3 & PI-HPM & acetic acid & $n$-propanol & 83.7 \\
4 & PI-HPM & acetic acid & $n$-butanol & 68.5 \\
5 & PI-HPM & $n$-propionic acid & methanol & 91.4 \\
6 & PI-HPM & $n$-propionic acid & ethanol & 80.7 \\
7 & PI-HPM & $n$-hexanoic acid & methanol & 78.9 \\
8 & PI-HPM & $n$-hexanoic acid & ethanol & 62.4 \\
9 & PI-HPM & oleic acid & methanol & $100^{\mathrm{b}}$ \\
10 & PI-HPM & oleic acid & ethanol & 100 \\
11 & PI-HPM & oleic acid & $n$-propanol & 82.3 \\
12 & PI-HPM & oleic acid & $n$-butanol & 76.9 \\
13 & fresh PI-HPM & oleic acid & methanol & $94.3^{\mathrm{c}}$ \\
14 & HPI & oleic acid & methanol & 20.7 \\
15 & HPM & oleic acid & methanol & 89.7 \\
16 & used PI-HPM & oleic acid & methanol & $89.1^{\mathrm{d}}$ \\
$17^{33}$ & SnO $_{2} / \mathrm{WO}_{3}$ & oleic acid & ethanol & ca. $90^{\mathrm{e}}$ \\
$18^{32}$ & ZSTA-15 & acetic acid & $n$-butanol & $57^{\mathrm{f}}$ \\
\hline
\end{tabular}

${ }^{\mathrm{a}}$ For entries 1-8: reflux, time $=6 \mathrm{~h}$, catalyst amount $=0.1 \mathrm{~g}$, acid: alcohol

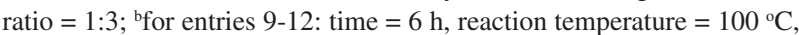
catalyst amount $=10 \mathrm{wt} . \%$ of oleic acid, acid:alcohol ratio $=1: 10$; cfor entries 13-16: time $=6 \mathrm{~h}$, reaction temperature $=80^{\circ} \mathrm{C}$, catalyst amount $=10 \mathrm{wt} . \%$ of oleic acid, acid:alcohol ratio $=1: 10 ;{ }^{\mathrm{d}}$ conversion was achieved after the fourth recycling of PI-HPM; ${ }^{e}$ reflux, time $=12 \mathrm{~h}$, catalyst amount $=0.1 \mathrm{~g}$, acid:alcohol ratio $=1: 120$; ${ }^{\mathrm{f}}$ time $=4 \mathrm{~h}$, reaction temperature $=80^{\circ} \mathrm{C}$, catalyst amount $=0.025 \mathrm{~g}$, acid:alcohol ratio $=1: 16$. PI-HPM: picolinic acid-12-molybdophosphoric acid hybrid complex; HPI: picolinic acid; HPM: 12-molybdophosphoric acid hybrid complex; ZSTA-15: zirconia-supported silicotungstic acid.

were obtained. The desired result was also achieved, that the PI-HPM can be easily separated by centrifugation from the reaction system, indicating that the complex presented good durability. The percentage of conversion of these acids with methanol followed the order: acetic acid $>n$-propionic acid $>n$-hexanoic acid, which can be explained on the basis of the strength of the reacting acids. ${ }^{32}$ Furthermore, the decrease of conversion for the esterification of acetic acid with different alcohols might be due to the increase of steric hindrance with the growth of alkyl chain of alcohols.

PI-HPM was also applied to the esterification of oleic acid with different alcohols. From Table 2, it can be seen that high conversion was obtained for the esterification of oleic acid with methanol or ethanol. The esterification of oleic acid with methanol was considered to be a main method for the synthesis of biodiesel. For comparison, esterification of oleic acid was carried out only in the presence of HPI or HPM. A conversion of 20.7 and $89.7 \%$ of oleic acid took place, respectively. After the reaction ended, however, it was difficult to separate the HPI and HPM due to the dissolution in reaction mixtures. Therefore, PI-HPM not only exhibited higher catalytic activity than HPM, but also overcame the difficulty of separation from esterification mixtures, which was the very purpose of using HPI to modify the HPM. Acid-base titration was performed to explain why PI-HPM has good catalytic activity. The results indicated that the capacity of acid sites increased from $11.88 \mathrm{mmol} \mathrm{g}^{-1}$ of HPM to $11.98 \mathrm{mmol} \mathrm{g}^{-1}$ of PI-HPM. For comparison, previous results for the esterification of oleic acid or acetic acid over some reported typical solid acid catalysts are also gave in Table 2 .

The effect of reaction parameters, including reaction time, temperature, mole ratio and catalyst dosage on esterification of oleic acid with methanol catalyzed by PIHPM were studied (Figure 6). The conversion of $94.3 \%$ of oleic acid was achieved at the mole ratio of alcohol to acid of 10:1, catalyst amount of $10 \mathrm{wt} . \%$ of oleic acid and reaction time of $6 \mathrm{~h}$ at $80{ }^{\circ} \mathrm{C}$. Conversion of $100 \%$ was obtained when temperature was increased to $100^{\circ} \mathrm{C}$.

After reaction, PI-HPM was separated from the reaction mixture only by simple filtration and washed with methanol. After drying the catalyst was reused with new charge of oleic acid and methanol. The result suggested that
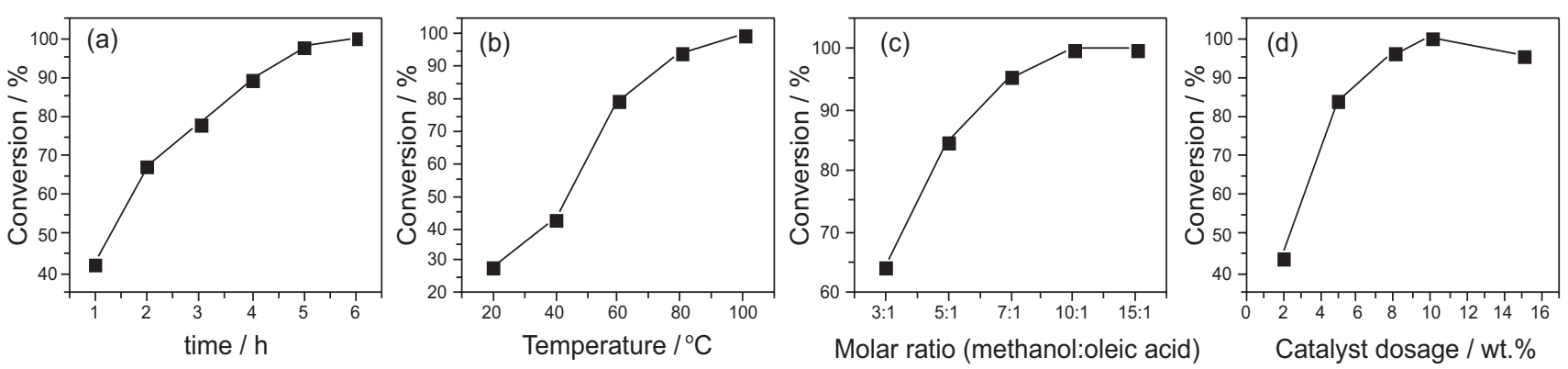

Figure 6. Effects of reaction parameters on the esterification of oleic acid. Reaction conditions: (a) reaction temperature $=100{ }^{\circ} \mathrm{C}$, catalyst amount $=10 \mathrm{wt} . \%$ of oleic acid, acid:alcohol ratio $=1: 10 ;(b)$ time $=6 \mathrm{~h}$, catalyst amount $=10 \mathrm{wt} . \%$ of oleic acid, acid:alcohol ratio $=1: 10 ;(\mathrm{c})$ time $=6 \mathrm{~h}$, reaction temperature $=100{ }^{\circ} \mathrm{C}$, catalyst amount $=10 \mathrm{wt} . \%$ of oleic acid; $(\mathrm{d})$ time $=6 \mathrm{~h}$, reaction temperature $=100{ }^{\circ} \mathrm{C}$, acid:alcohol ratio $=1: 10$. 
PI-HPM catalyst was reusable with little loss in activity. A conversion $89.1 \%$ was achieved after the fourth recycling (Table 2, entry 16), suggesting that the PI-HPM was stable and commendably compensated the disadvantage of raw HPM.

To verify the recovery of PI-HPM catalyst, XRD and IR measurements were performed after four recycles; the results are shown in Figure 3e and Figure 4d, respectively. The XRD patterns of catalyst before and after reaction were almost identical, which indicated that there was no obvious change for the catalyst structure after esterification. For IR spectrum, the four Keggin characteristic bands in the range of $700-1100 \mathrm{~cm}^{-1}$ were all observed. All these results indicated the highly chemical and structural stability of PI-HPM catalyst.

Compared with the IR spectrum of fresh PI-HPM, however, new infrared bands at 2925, 2855 and $1740 \mathrm{~cm}^{-1}$ were observed for the recycled catalyst spectrum, which is similar with the IR spectrum of methyl oleate, supported by the Spectral Database for Organic Compounds (SDBS No. 8872). That is, the catalyst was attached to methyl oleate after reaction, which might cause the slight reduction in catalytic activity of the reused catalyst. Therefore, more effective treatment method should be developed to optimize the catalytic activity of reused catalyst.

\section{Conclusions}

In this work, a novel HPM-based complex was prepared by the modification of HPM with HPI, and the complex was applied in esterification reaction as heterogeneous catalyst to evaluate its acid-catalytic activity. The characterization results suggested the complex still retained the Keggin ion structure of HPM. The complex simultaneously possessed high catalytic activity and good durability in reaction mixtures, indicating that PI-HPM was an excellent heterogeneous catalyst for esterification. Compared with commercial mineral acid, PI-HPM was more benign from the environmental protection point of view.

\section{Supplementary Information}

Supplementary information is available free of charge at http://jbcs.sbq.org.br as PDF file.

\section{Acknowledgments}

The authors are grateful for the support of the National Natural Science Foundation of China (21101086), the Doctor Foundation of Shandong Province (BS2010CL011) and the Foundation of Liaocheng University (318011406).

\section{References}

1. Vonnera, A.; Castela, C.; Schaer, E.; Moreliere, A.; Chem. Eng. Res. Des. 2015, 93, 602.

2. Ozorio, L. P.; Pianzolli, R.; Mota, M. B. S.; Mota, C. J. A.; J. Braz. Chem. Soc. 2012, 23, 931.

3. Ladera, R. M.; Ojeda, M.; Fierro, J. L. G.; Rojas, S.; Catal. Sci. Technol. 2015, 5, 484.

4. Gong, S.; Liu, L.; Cui, Q.; Ding, J.; J. Hazard. Mater. 2010, $178,404$.

5. Oyama, K.; Tidwell, T. T.; J. Am. Chem. Soc. 1976, 98, 947.

6. Sawant, D. P.; Vinu, A.; Justus, J.; Srinivasu, P.; Halligudi, S. B.; J. Mol. Catal. A: Chem. 2007, 276, 150.

7. Ahmed, A. I.; El-Hakam, S. A.; Abd Elghany, M. A.; Abo ElYazeed, W. S.; Appl. Catal., A 2011, 407, 40.

8. Kozhevnikova, E. F.; Derouane, E. G.; Kozhevnikov, I. V.; Chem. Commun. 2002, 33, 1178.

9. Palkovits, R.; Tajvidi, K.; Ruppert, A. M.; Procelewska, J.; Chem. Commun. 2011, 47, 576.

10. Wang, L.; Dong, X.; Jiang, H.; Li, G.; Zhang, M.; Catal. Commun. 2014, 56, 164.

11. Kuzminska, M.; Backov, R.; Gaigneaux, E. M.; Catal. Commun. 2015, 59, 222.

12. Li, K.; Wang, C.; Wang, I.; Wang, C.; Appl. Catal., A 2011, 392, 180.

13. Zhu, Y.; Hua, Z.; Song, Y.; Wu, W.; Zhou, X.; Zhou, J.; Shi, J.; J. Catal. 2013, 299, 20.

14. Boffito, D. C.; Crocellà, V.; Pirola, C.; Neppolian, B.; Cerrato, G.; Ashokkumar, M.; Bianchi, C. L.; J. Catal. 2013, 297, 17.

15. Gao, X.; Zhu, S.; Li ,Y.; Catal. Commun. 2015, 62, 48.

16. Liu, T.; Li, Z.; Li, W.; Shi, C.; Wang, Y.; Bioresour. Technol. 2013, 133, 618.

17. Jagadeeswaraiah, K.; Balaraju, M.; Sai Prasad, P. S.; Lingaiah, N.; Appl. Catal., A 2010, 386, 166.

18. Langpape, M.; Millet, J. M. M.; Ozkan, U. S.; Boudeulle, M.; J. Catal. 1999, 181, 80.

19. Cardoso, L. A. M.; Alves Jr., W.; Gonzaga, A. R. E.; Aguiar, L. M. G.; Andrade, H. M. C.; J. Mol. Catal. A: Chem. 2004, $209,189$.

20. Heravi, M. M.; Khorasani, M.; Derikvand, F.; Oskooie, H. A.; Bamoharram, F. F.; Catal. Commun. 2007, 8, 1886.

21. Bhorodwaj, S. K.; Dutta, D. K.; Appl. Catal., A 2010, 378, 221.

22. Lu, M.; Wei, Y. G.; Xu, B. B.; Cheung, C. F. C.; Peng, Z. H.; Powell, D. R.; Angew. Chem., Int. Ed. 2002, 41, 1566.

23. Song, I. K.; Kaba, M. S.; Barteau, M. A.; J. Phys. Chem. 1996, 100, 17528.

24. Leng, Y.; Qiu, X.; Jiang, P.; Wang J.; Chin. J. Catal. 2012, 33, 1224.

25. Gong, S.; Lu, J.; Wang, H.; Liu, L.; Zhang, Q.; Appl. Energy 2014, 134, 283. 
26. Chen, L.; Wang, X.; Guo, X.; Guo, H.; Liu, H.; Chen, Y.; Chem. Eng. Sci. 2007, 62, 4469.

27. Ma, J.; Ye, X.; Wu, Y.; Chin. J. Catal. 1991, 12, 443.

28. Carriazo, D.; Domingo, C.; Martín, C.; Rives, V.; J. Solid State Chem. 2008, 181, 2046.

29. Selli, E.; Forni, L.; Microporous Mesoporous Mater. 1991, 31, 129.

30. Kim, H. J.; Jeon, Y. K.; Park, J. I.; Shul, Y. G.; J. Mol. Catal. A: Chem. 2013, 378, 232.
31. Altıokka, M. R.; Akbay, E.; Him, Z.; J. Mol. Catal. A: Chem. 2014, 385, 18.

32. Parida, K. M.; Mallick, S.; J. Mol. Catal. A: Chem. 2007, 275, 77.

33. Sarkar, A.; Ghosh, S. K.; Pramanik, P.; J. Mol. Catal. A: Chem. 2010, 327, 73 .

Submitted: August 20, 2015

Published online: December 16, 2015 